\title{
PRESERVAÇÃO DO PATRIMÔNIO HISTÓRICO-EDUCATIVO: ACERVOS ESCOLARES DE CAMPINAS
}

\author{
Isabela F. Martins ${ }^{\star}$, Jovana C. F. Silva*, Tamiris F. Souza*, Wagner B. Castro*, Giovana D. Ruffi, Sílvia R. Cason, \\ Maria Cristina Menezes.

\section{Resumo}

Este trabalho desenvolveu-se no âmbito das pesquisas coordenadas pela Profa. Maria Cristina MenezesFE/UNICAMP, em prol da preservação dos acervos históricos de antigas escolas públicas estaduais de Campinas. As atividades deste projeto pautaram-se pela organização e fertilização de dois espaços museológicos em duas escolas estaduais centenárias de Campinas EE "Carlos Gomes", $1^{\text {a }}$ Escola Normal de Campinas e EE "Culto à Ciência", $1^{\circ}$ Ginásio de Campinas. O trabalho de preservação exigiu as ações de desinfestação, higienização, identificação e descrição de fontes dos vários acervos que compõem o arquivo histórico das instituições. Tal trabalho exigiu pesquisa e interlocução com outras Universidades do Brasil e do Exterior. Os meses finais de 2016 e $1^{\circ}$ semestre de 2017 foram fundamentais para a conquista e a constituição de espaços museológicos nas instituições. A organização de duas exposições, nas duas instituições supracitadas, comemorativas dos 50 anos de formatura de duas turmas nas duas escolas, respectivamente, em especial, na EE Carlos Gomes funcionou estrategicamente para ancorar a formação do museu da Escola Normal de Campinas e instituições que ela comportou, com a conquista de amplo espaço museológico para este museu. Considera-se que o trabalho em equipe tenha sido o grande ativador desse feliz desenlace. Ensino médio, graduação, pós-graduação, docentes da escola pública e da universidade trabalhando juntos em prol da preservação do patrimônio histórico-educativo.

Palavras-chave: patrimônio histórico-educativo, cultura escolar, história da educação

\section{Introdução}

As Escolas Estaduais "Carlos Gomes" e "Culto à Ciência" são instituições centenárias da cidade de Campinas, que se inserem no projeto "Preservação do Patrimônio Histórico Educativo: acervos escolares de Campinas", coordenado pela Profa. Dra. Maria Cristina Menezes e desenvolvido no âmbito do CIVILIS, Grupo de Estudos e Pesquisa em História da Educação, Cultura Escolar e Cidadania, FE/UNICAMP. Durante todo o desenvolvimento do projeto a equipe se detém sobre a preservação e a organização de documentos, livros e materiais de ensino, em especial, antigos instrumentos científicos, para os quais se necessita conhecimentos específicos, através de leituras e discussão em grupo, além de capacitação proporcionada pela parceria com outros centros, como o AEL/UNICAMP, em conservação; além dos encontros anuais pela RIDPHE com equipes de outras universidades nacionais e internacionais. Nos encontros podemos divulgar nossos trabalhos e conhecer outras experiências, sobretudo, visando o avanço pela equipe do projeto para a conservação dos itens e a musealização dos mesmos nos espaços escolares.

\section{Resultados e Discussão}

Além da contribuição da pesquisa para o entendimento e desenvolvimento de práticas de conservação, as atividades deste projeto pautaram-se pela organização e fertilização de dois espaços museológicos em duas escolas estaduais centenárias de Campinas EE "Carlos Gomes", $1^{\text {a }}$ Escola Normal de Campinas e EE "Culto à Ciência", $1^{\circ}$ Ginásio de Campinas. O trabalho de preservação exigiu as ações de desinfestação, higienização, identificação e descrição de fontes dos vários acervos que compõem o arquivo histórico das instituições. Tal trabalho exigiu pesquisa e interlocução com outras Universidades do Brasil e do Exterior. Os meses finais de 2016 e $1^{\circ}$ semestre de 2017 foram fundamentais para a conquista e a constituição de espaços museológicos nas instituições. A organização de duas exposições, nas duas instituições supracitadas, comemorativas dos 50 anos de formatura de duas turmas nas duas escolas, respectivamente, em especial, na EE Carlos Gomes funcionou estrategicamente para ancorar a formação do museu da Escola Normal de Campinas e instituições que ela comportou, com a conquista de amplo espaço museológico para este museu.

\section{Conclusões}

Considera-se que o trabalho em equipe tenha sido o grande ativador desse feliz desenlace. Ensino médio, graduação, pós-graduação, docentes da escola pública e da universidade trabalhando juntos em prol da preservação do patrimônio histórico-educativo.

\section{Agradecimentos}

Agradecemos ao apoio PRP/UNICAMP/CNPq e Escolas Estaduais "Carlos Gomes" e "Culto à Ciência" de Campinas.

DOMINGUEZ, Pablo Alvarez (coord). Los museos pedagógicos en España: entre la memoria y la creatividad. Gijon: Trea, 2016.

MENEZES, M. C. (coord.) et al. Inventário Histórico Documental. Escola Normal de Campinas (1903-1976): De Escola Complementar a Instituto de Educação. Campinas, SP: FE/UNICAMP, 2009.

CASSARES, N. C. Como fazer a conservação preventiva em arquivos e bibliotecas. São Paulo: Arquivo do estado/Imprensa Oficial, 2000.

XXV Congresso de Iniciação Científica da UNICAMP 